\title{
INDEX OF PAPERS PUBLISHED IN THIS VOLUME ARRANGED ACCORDING TO NAMES OF AUTHORS
}

[The numbers refer to pages.]

Burchnall, J. L. ... Chambers, LL. G.... Clunie, J. ... $\ldots$

Davidson, P. M. ...

... Some theorems in group velocity, 122 .

... $\quad . . \quad$ Rings with central idempotent or nilpotent elements, 157.

Evans, Arwel $\quad \ldots \quad \ldots \quad$ A theorem on general regular transformations of series, 105.

Fabian, William ... ... A generalised hypergeometric function, 151.

Fuchs, W. H. J. ... ... On the growth of functions of mean type, 53.

Harington, C. F. and Hyslop, J. M.

Hsu, L. C. ... ... Hyslop, J. M. and Harington, C. F.

Kustaanheimo, Paul

.. A method of evaluating certain determinants, 100.

... Reflection of a wave by a cylindrical mirror, $\mathbf{1 4 5}$.

... On a certain series of Abel, 132. method, 28.

... Note on an abstract inversion principle, 71 . method, 28.
... An analogue for strong summability of Abel's summability

... An aralogue for strong summability of Abel's summability

... A note on the transformability of spherically symmetric metrics, 13.

Lakin, A. and Slater L. J. Two proofs of the ${ }_{8} \Psi_{6}$ summation theorem, 116.

Macintyre, Sheila Scott ... An interpolation series for integral functions, 1 .

Mackie, A. G. ... ... An application of Hankel transforms in axially symmetric potential flow, 128.

Perfect, Hazel $\quad \ldots \quad$... Pythagorean orthogonality in a normed linear space, 168.

Ponting, F. W, ... ‥ A type of alternant, 20.

Popova, Helen $\quad \ldots \quad \ldots \quad$ Logarithmetics of finite quasigroups (I), 74; (II), 109.

Rushforth, J. M. ... ... A generalisation of Jacobi's fundamental formulae, 17.

Shenton, L. R. ... $\quad \ldots$ A determinantal expansion for a class of definite integral. Part 1, 44.

Generalised algebraic continued fractions related to definite integrals, 170 .

Slater, L. J. and Lakin, A. Two proofs of the ${ }_{6} \Psi_{6}$ summation theorem, 116.

Spain, B. ... ... $\quad \ldots$ Interpolated derivatives, 166.

Stein, P. ... $\quad \ldots \quad$... An extension of a formula of Cayley, 91.

Ursell, H. D. ... ... Simultaneous linear recurrence relations with variable coefficients, 183.

Wallace, Andrew, H. ... A note on the Capelli operators associated with a symmetric matrix, 7.

Generalised Young tableaux, 35.

Walls, Nancy $\quad \ldots \quad \ldots \quad$ On a certain type of space-tableau, 82 .

Walsh, C. E. $\quad \ldots \quad \quad \ldots \quad$ A note on convergence factors, 154.

Wright, E. M. ... ... A simple proof of a theorem of Landau, 87 . 